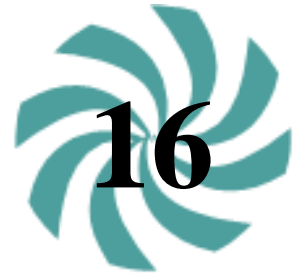

Tecnociencia, Vol. 23, $\mathrm{N}^{\circ} 1: 315-331$

\title{
HONGOS PATÓGENOS EN LA PRODUCCIÓN DE CAMARÓN MARINO, Litopenaeus vannamei (BOONE), PANAMÁ.
}

\author{
${ }^{1}$ Francisco Bernal, (D) ${ }^{1}$ Linda Yangiiés, (D) ${ }^{2}$ Martha de Von \\ Chong, ID ${ }^{3}$ María Isabel Ashaw Muñoz \\ ${ }^{1}$ Escuela de Biología, Facultad de Ciencias Naturales, Exactas y Tecnología, \\ Universidad de Panamá, C.R.U.C. ² Departamento de Microbiología, Facultad de \\ Ciencias Naturales, Exactas y Tecnología, Universidad de Panamá, C.R.U.C. \\ ${ }^{3}$ Departamento de Matemática, Facultad de Ciencias Naturales, Exactas y Tecnología, \\ Universidad de Panamá, C.R.U.C. e-mail: franciscobernal20@gmail.com; \\ lindayanguez@hotmail.com; martha.chaves@up.ac.pa.maria.ashaw@up.ac.pa
}

\section{RESUMEN}

Se determinó la microflora fúngica de camarones peneidos presente en los segmentos abdominales, pleópodos, pereiópodos, urópodos y telson, a través del aislamiento en Agar papa dextrosa (PDA) y agar Sabouraud (ASD), para su posterior identificación taxonómica. Tres fincas camaroneras del Distrito de Aguadulce, Provincia de Coclé, República de Panamá fueron seleccionadas y de cada una de ellas se colectaron individuos para el examen clínico. Se determinó necrosis cuticular en el 55,76 \% de los camarones y en el 44,24\% anomalidades macroscópicas externas. La población fúngica encontrada perteneció a los siguientes géneros: Aspergillus, Fusarium y Penicillium; siendo los géneros de mayor incidencia Fusarium y Aspergillus.

\section{PALABRAS CLAVES}

Necrosis, microflora, Fusarium., Penicillium, Aspergillus. 


\title{
FUNGES IN SEA SHRIMP PRODUCTION SYSTEMS, Litopenaeus vannamei (BOONE), PANAMA.
}

\begin{abstract}
The Fungal Microflora was determined on peneid shrimp, present in the leopods, periopods, uropods and telson, through aisle, in PDA and ASD, for its later taxonomic identification. Three Shrimp Farms from Aguadulce District, Cocle Province, Panama were selected and from ach one of them individuals were collected to perform clinical analysis, cuticular necrosis was determined in 55, 76\% and 44,24 \% with external macroscopical abnormalities. The fungi population found belongs to the genres: Aspergillus, Fusarium, and Penicillium; being the most higher incidence rate genre the Fusarium and Aspergillus.
\end{abstract}

\section{KEYWORDS}

Necrosis, Microflora, Fusarium, Penicillium, Aspergillus.

\section{INTRODUCCIÓN}

Según Tizol, Jaime, Laria, Machado, y Silveira (2003), el camarón blanco Litopenaeus vannamei es originario de la costa oeste del Pacífico de América Latina, desde Perú en el sur hasta México en el norte. El desarrollo de la acuicultura en Panamá contaba con 9 354,59 ha para el cultivo de camarones marinos (FAO, 2006) y en el 2009, la Autoridad de Recursos Acuáticos de Panamá (ARAP) reportaba 9 741,48 ha de producción, distribuidas en 77 fincas, de las cuales, 37 fincas están activas. En la actualidad, el cultivo de mayor relevancia en Panamá lo constituye el camarón: Litopenaeus vannamei, debido a su alto crecimiento y alta capacidad de resistencia o tolerancia. Esfuerzos realizados, en 2018, Panamá alcanza una producción de 14128 372,94 libras de esta especie.

El camarón blanco como especie resistente a enfermedades, ha sido objeto de estudios enfocados en conocer cómo funcionan sus mecanismos de defensa, los cuales contribuirán al desarrollo planeado de la producción y el cultivo (Alpuche, Agundis, Solórzano, \& Pereira, 2005). El hospedero, el patógeno y el ambiente de cultivo interactúan entre sí afectando los cultivos acuícolas. Investigaciones sobre este tópico han sido documentados por varios autores, quienes consideran como principales agentes infecciosos a los virus, bacterias y hongos (Ochoa, 2004). 
Actualmente, mucho se ha estudiado en materia de investigación, virus y bacterias como agentes infecciosos, al igual para el caso de hongos (Lozano, Marrujo, \& Abad, 2012). Por lo anterior, y la importancia económica que reviste la principal especie de camarón cultivada en Panamá (L. vannamei), es relevante determinar la microflora fúngica presente en los segmentos abdominales, pleópodos, pereiópodos, urópodos y telson, a través del aislamiento e identificación taxonómica de hongos filamentosos.

\section{MATERIALES Y MÉTODOS}

Esta investigación es de tipo descriptiva, donde se determinó la presencia o ausencia de hongos patógenos en fincas de producción de camarón blanco. Los sitios seleccionados para la colecta de los camarones estaban ubicados en el Distrito de Aguadulce, Provincia de Coclé, República de Panamá, con precipitación de 1500 mm/año; clima húmedo tropical, con prolongada temporada de lluvia de mayo a diciembre y una corta temporada seca de enero a mayo.

Las fincas seleccionadas para el estudio fueron: La Finca A que siguió el protocolo de manejo de producción intensiva del camarón, con 372 individuos; la Finca B donde se empleó tecnología media de producción, con 336 individuos y Finca $\mathrm{C}$ que aplicó tecnología científica para validar procesos de producción con 306 individuos. Las muestras fueron colectadas en estanques de las fincas antes mencionadas. Se realizaron seis muestreos en total por finca; dos veces al mes, de enero a marzo del 2019, y se tomaron las muestras de un máximo de cinco estanques por finca para formar la muestra total. En cada estanque, se definen 5 puntos de colecta para considerar la población final de animales. Para ello, se utilizó una atarraya de muestreo conforme se tiene definido en el plan de manejo por finca.

Los organismos fueron transportados con el menor estrés posible y con las mejores condiciones siguiendo la metodología establecida por (Jaime, Galindo, Laria, Cupul, \& Vega, 2008). La revisión microscópica

se realizó en el laboratorio de microbiología de la Universidad de Panamá, sede Coclé, siguiendo lo establecido en (Cuéllar, Lara, Morales, De Gracia, \&Suarez, 2010). 
Se examinaron los pleópodos, pereiópodos, urópodos, telson, abdomen y músculo esquelético (Cuéllar et al., 2010). En el análisis del estado de salud de las muestras se utilizó la metodología de (Morales Covarrubias, 2010). La necrosis cuticular o alguna lesión se observó en la anatomía externa de cada camarón con la ayuda de un microscopio estereoscópico binocular, Modelo VE-S1.

Se estableció el muestreo sobre la base de la frecuencia en estas fases lunares para determinar si hubo alguna relación con el aumento de individuos con necrosis (García, \& Le Reste, 1986). Para el caso de la temperatura y la salinidad los datos mensuales promedios fueron reportados por las autoridades administrativas de cada Finca.

Las muestras obtenidas con lesiones necróticas del exoesqueleto fueron sembradas en medio de cultivo agar papa dextrosa (PDA) y Agar Sabouraud Dextrosa (DSA) e incubadas a $28{ }^{\circ} \mathrm{C}$ durante 15 días, con observaciones diarias con un régimen de 12 horas luz y 12 horas de oscuridad para lograr la esporulación del hongo, siguiendo la metodología correspondiente a Cañedo, y Ames (2004) y de Olvera, López y Rosales, (2012).

La caracterización morfológica macroscópicas se realizó en base a la forma, tamaño, color, crecimiento, tipo del micelio aéreo y reverso del cultivo (Alvarado, 2005). Las cepas fúngicas con características macroscópicas similares se agruparon en morfotipos para su identificación taxonómica, se empleó la técnica de microcultivo en cámara húmeda (Castro, Serrano, \& León, 2015).

Se cortaron pequeños bloques de agar PDA y DSA, a los cuales, se les colocó pequeños segmentos hifales. Los microcultivos fueron incubados a $28{ }^{\circ} \mathrm{C}$ por 48 a 72 horas, o el tiempo necesario para su crecimiento y posterior observación microscópica de estructuras reproductivas características de hongos, las cuales eran identificadas taxonómicamente (Castro, et al., 2015). 


\section{RESULTADOS}

De 1015 individuos seleccionados, 372, 336 y 307 correspondían a las Fincas A, B, y C, respectivamente. Del total de individuos, 566 individuos $(55,76 \%)$ presentaron signos evidentes de necrosis cuticular. Se identificaron 145, 257 y 164 individuos con necrosis en las Fincas A, $\mathrm{B}$, y C, respectivamente. Finalmente, se observó en la Finca B mayor cantidad de casos con necrosis, $45,41 \%$ y en la Finca A el mayor porcentaje de individuos con anormalidades macroscópicas, 50,56\% (Tabla 1).

Tabla 1

Número de individuos con necrosis y otras afecciones macroscópicas por fincas, por mes.

\begin{tabular}{|c|c|c|c|c|c|c|c|c|}
\hline \multirow{2}{*}{ Finca } & \multicolumn{2}{|c|}{ Enero } & \multicolumn{2}{c|}{ Febrero } & \multicolumn{2}{c|}{ Marzo } & \multicolumn{2}{c|}{ Total } \\
\cline { 2 - 9 } & Necrosis & $\begin{array}{c}\text { Afecciones } \\
\text { macrosćpicas }\end{array}$ & Necrosis & $\begin{array}{c}\text { Afecciones } \\
\text { macrosćpicas }\end{array}$ & Necrosis & $\begin{array}{c}\text { Afecciones } \\
\text { macroscópicas }\end{array}$ & Necrosis & $\begin{array}{c}\text { Afecciones } \\
\text { macrosé́picas }\end{array}$ \\
\hline A & 48 & 80 & 48 & 71 & 49 & 76 & 145 & 227 \\
\hline B & $\mathbf{9 2}$ & 25 & $\mathbf{8 8}$ & 21 & $\mathbf{7 7}$ & 33 & 257 & 79 \\
\hline C & 48 & 57 & 59 & 41 & 57 & 45 & 164 & 143 \\
\hline
\end{tabular}

Al comparar los estanques muestreados, se observó que la menor prevalencia de la enfermedad se dio cuando se siguió el protocolo de manejo de producción intensiva del camarón, en la Finca A (Fig. 1). 
Figura 1

Números de individuos con necrosis según manejo de producción.

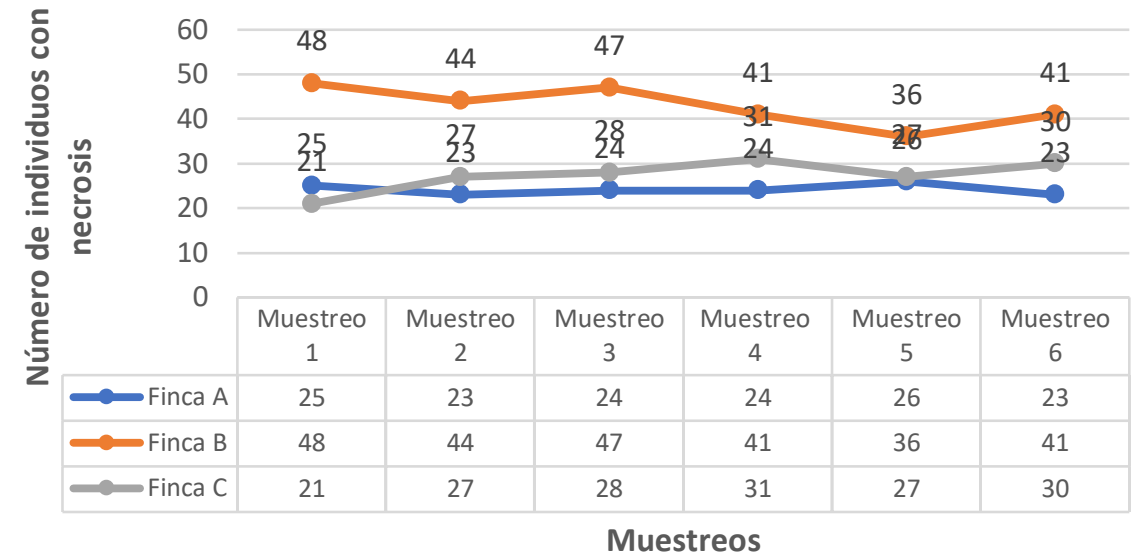

El mayor número de casos con necrosis se presentó en la Finca B (79 \%) durante la luna nueva y el menor número de casos durante la luna llena en la Finca A (37\%), Tabla 2.

Tabla 2

Número de individuos con necrosis o con afecciones macroscópicas colectados en cada una de las fincas, según luna.

\begin{tabular}{|c|c|c|c|c|}
\hline \multirow{2}{*}{ Finca } & \multicolumn{2}{|c|}{$\begin{array}{c}\text { Total de Individuos } \\
\text { Luna Nueva }\end{array}$} & \multicolumn{2}{c|}{$\begin{array}{c}\text { Total de Individuos } \\
\text { Luna Llena }\end{array}$} \\
\cline { 2 - 5 } & Necrosis & $\begin{array}{c}\text { Afecciones } \\
\text { macroscópicas }\end{array}$ & Necrosis & $\begin{array}{c}\text { Afecciones } \\
\text { macroscópicas }\end{array}$ \\
\hline A & $75(41 \%)$ & $107(59 \%)$ & $70(37 \%)$ & $120(63 \%)$ \\
\hline B & $131(79 \%)$ & $35(21 \%)$ & $126(74 \%)$ & $44(26 \%)$ \\
\hline C & $76(49 \%)$ & $79(51 \%)$ & $84(57 \%)$ & $64(43 \%)$ \\
\hline
\end{tabular}

Se relacionó la abundancia de individuos necróticos con los parámetros fisicoquímicos (salinidad y temperatura) mediante una proyección lineal y se pudo observar que a medida que la temperatura iba aumentando, durante los meses de enero a marzo, se dio un incremento de los casos de necrosis en las Fincas A y C, mientras que en la Finca B se observó un decremento (Fig. 2). De igual manera, a medida que la 
salinidad iba disminuyendo, durante el periodo de estudio, se dio un aumento de los casos de necrosis en la Finca C, mientras que en la Finca B se observó una disminución (Fig. 3).

Figura 2

Individuos con necrosis, según temperatura promedio.

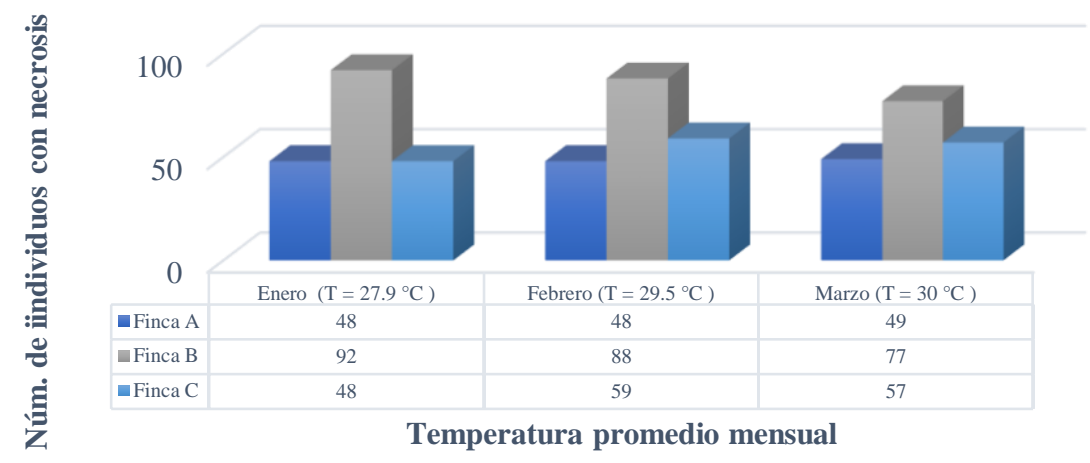

- Finca A Finca B $\quad$ Finca C

Figura 3.

Individuos con necrosis, según salinidad promedio.

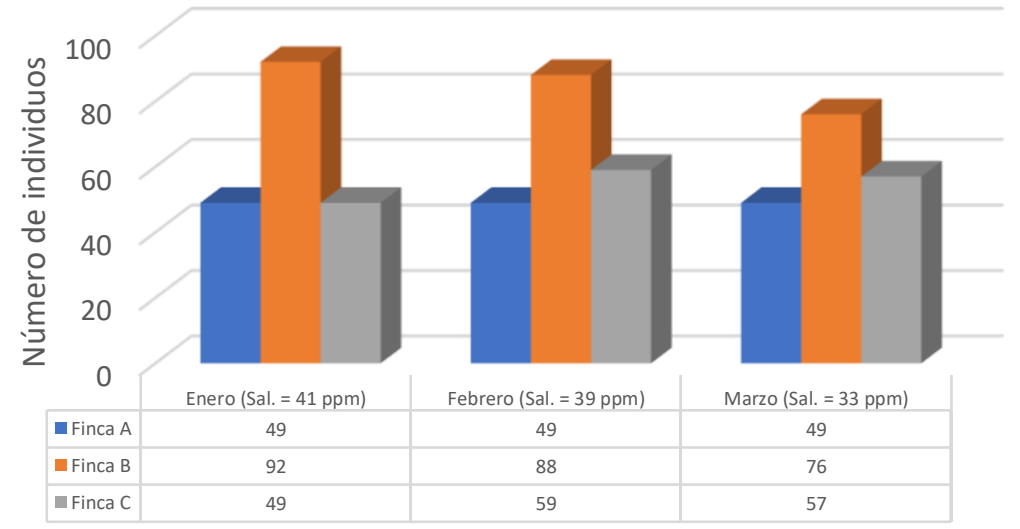

Se relacionó los parámetros ambientales, temperatura y salinidad para ver su comportamiento durante el estudio. Se observó que hay una relación inversa proporcional entre ellas (Fig. 4). 
Figura 4.

Relación de la temperatura y la salinidad.

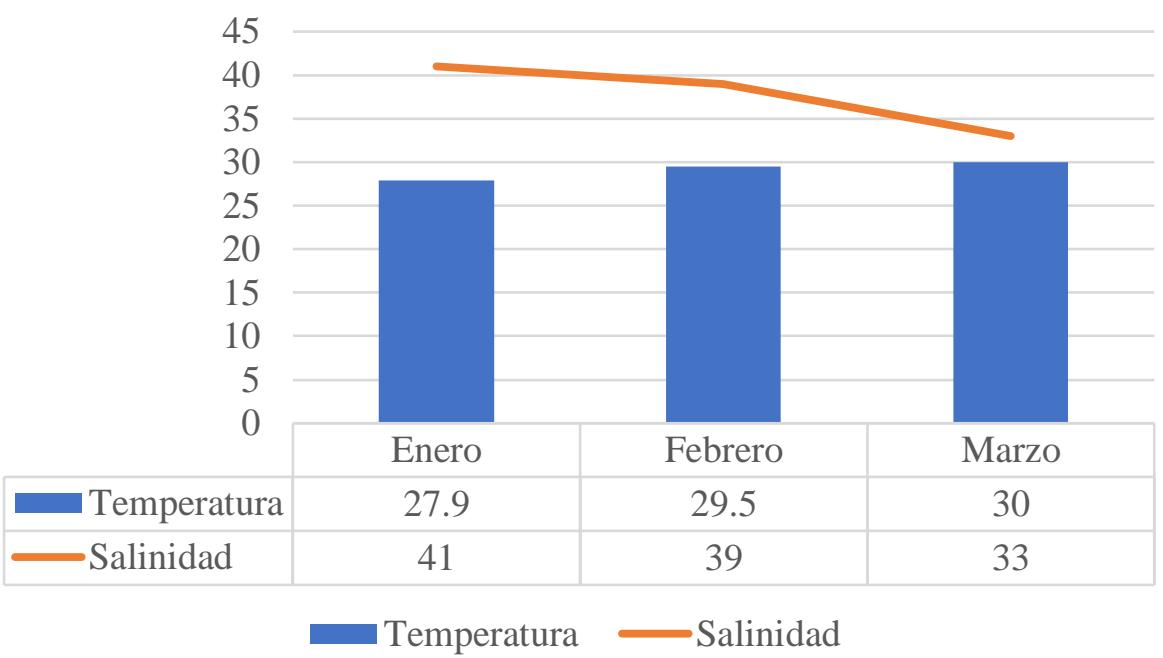

En el examen clínico externo realizado a cada uno de los camarones capturados en los estanques de las tres fincas estudiadas, se encontró individuos afectados con presencia de necrosis cuticular en el área abdominal, urópodos, pereiópodos, pleópodos y telson, así como algunas malformaciones macroscópicas (Fig. 5). 
Figura 5

Necrosis cuticular en el área del abdomen, telson y malformaciones $(\mathrm{N})$ y en el área dorsal (M).

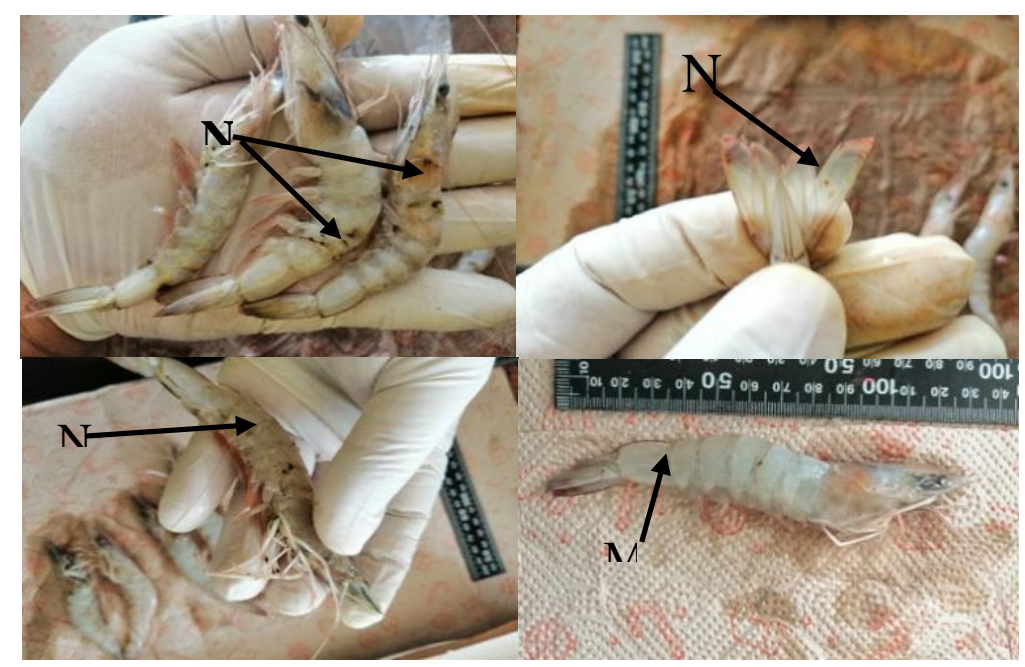

Se obtuvieron 190 aislamientos, de los cuales 106 (56\%) mostraron crecimiento fúngico según la clasificación por morfotipos de Moller, Ch. (1995). Se identificaron taxonómicamente los géneros: Fusarium sp. (Fig. 6), Aspergillus sp. (Fig. 7) y Penicillium sp. (Fig. 8) correspondiendo categóricamente: $65 \%$ de Fusarium sp., $21 \%$ de Aspergillus sp., $14 \%$ del género Penicillium sp. Se determinó que los individuos muestreados en la Finca B fueron los más afectados por Fusarium sp. respecto a la Finca A. El hongo que afectó los individuos de la Finca C correspondió al género Aspergillus sp. (Tabla 3).

Tabla 3

Aislamientos a partir de tejidos con necrosis cuticular por finca en estudio.

\begin{tabular}{|c|c|c|c|c|c|}
\hline Finca & Cultivos & $\begin{array}{l}\text { Penicillium } \\
\text { sp. }\end{array}$ & $\begin{array}{l}\text { Aspergillus } \\
\text { sp. }\end{array}$ & $\begin{array}{l}\text { Fusarium } \\
\text { sp. }\end{array}$ & Deuteromicetos \\
\hline A & 68 & 15 & 0 & 23 & 30 \\
\hline B & 87 & 0 & 13 & 46 & 28 \\
\hline C & 35 & 0 & 9 & 0 & 26 \\
\hline Total & 190 & 15 & 22 & 69 & 84 \\
\hline
\end{tabular}


Figura 6

Estructuras microscópicas de Fusarium spp. cultivado en agar Sabouraud. (A) Microconidias, (B, C) Macroconidias (D) Clamidosporas.

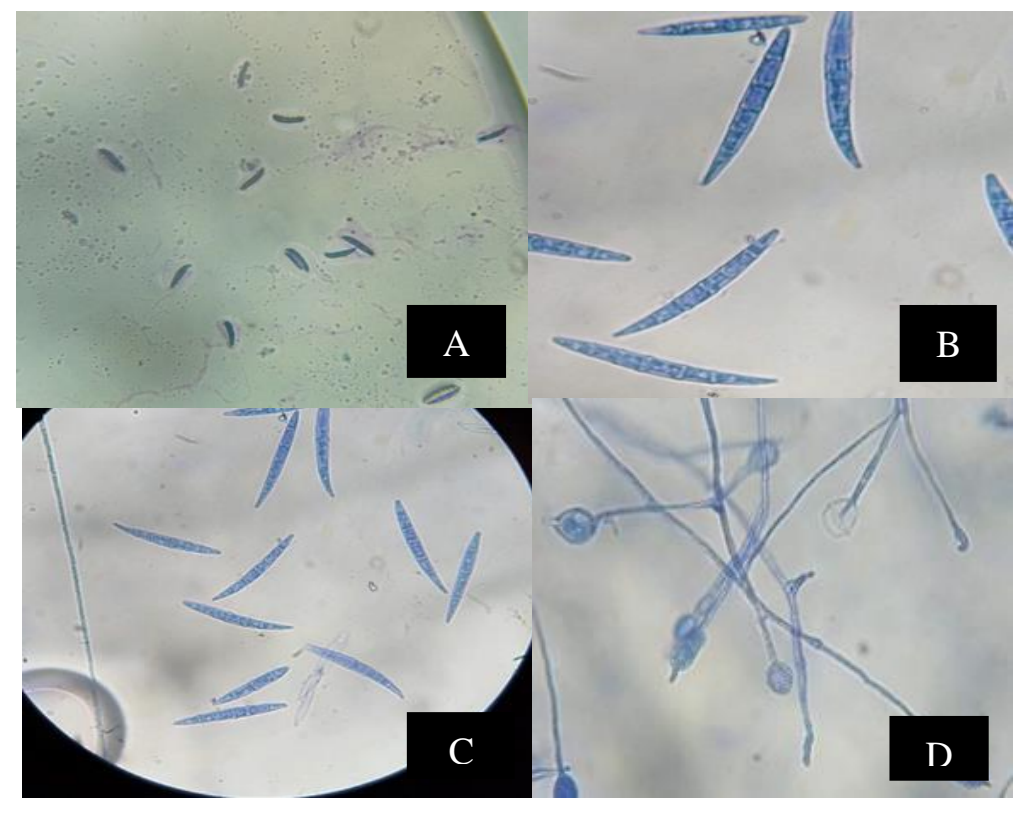

Figura 7

Aspergillius sp.

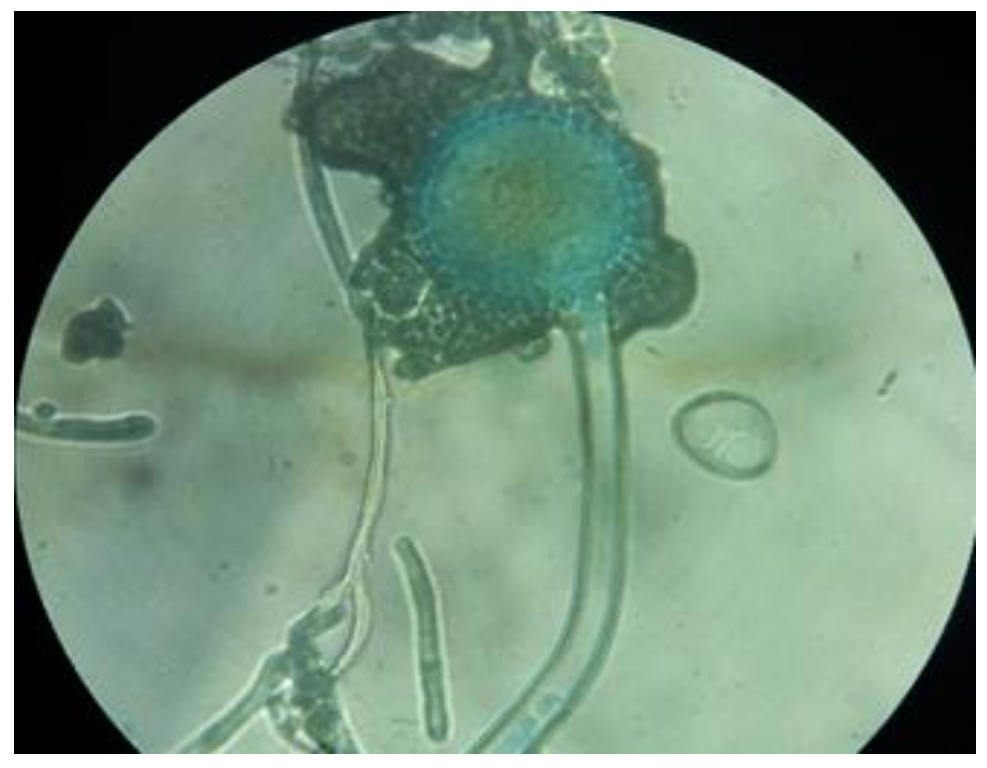

Tecnociencia, Vol. 23, $N^{\circ} 1$ 
Figura 8

Penicillium $s p$.

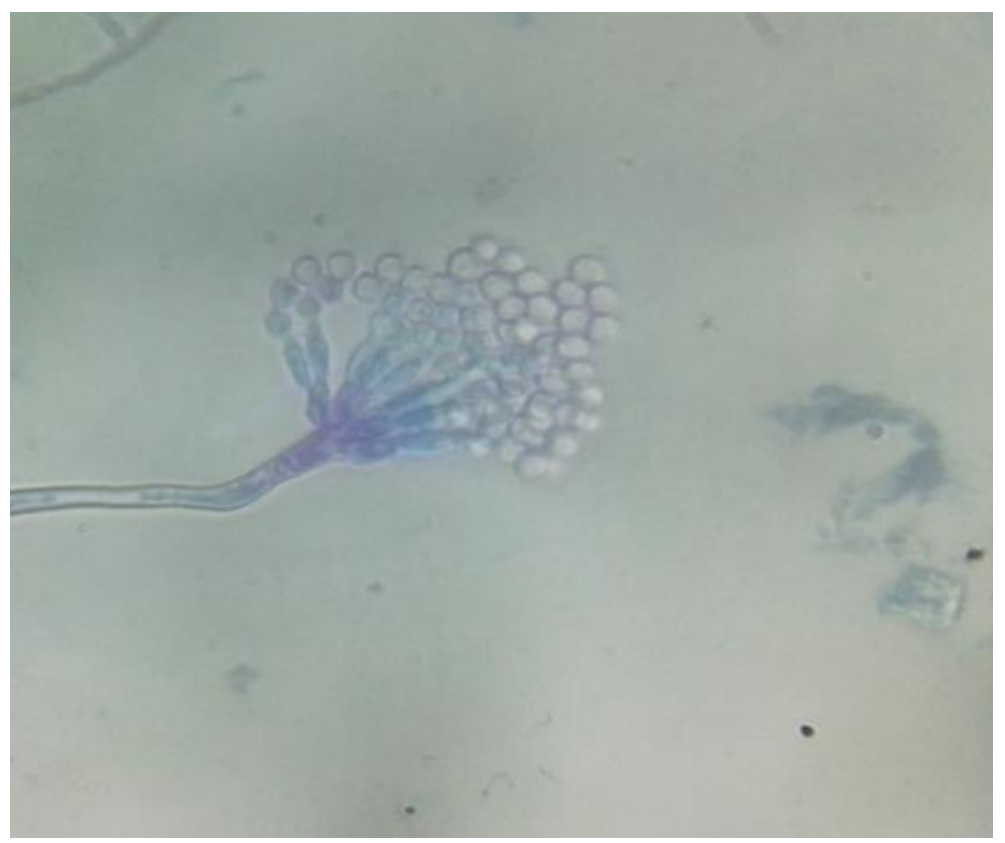

\section{DISCUSIÓN}

Las enfermedades infecciosas afectan las producciones acuícolas; causando estas un gran impacto en aspectos productivos y económicos. Esta investigación demostró que un $45 \%$ de los individuos presentaron lesiones características de la enfermedad conocida como necrosis cuticular, signo que evidencia que se deben mejorar las condiciones de manejo acuícola para estas fincas.

En el cultivo de camarón blanco es importante la aplicación de tecnologías que garanticen la salud de los animales y la prevención de enfermedades fúngicas. Por esta razón, en el presente estudio, el empleo del protocolo de producción intensiva llevada a cabo por la Finca A muestra el menor grado de contaminación de los organismos con necrosis cuticular (25\%) (Uzcátegui \& Solano, 2016).

Para el caso de la fase, Luna Nueva, se evidenció el mayor número de casos de necrosis cuticular en la Finca B; esto confirma lo escrito por 
García y Le Reste (1986) donde señala que es el momento ideal para cosechar más individuos.

El parámetro temperatura influye en el metabolismo y los procesos enzimáticos de digestión, trayendo consecuencias letales, como es el caso de las enfermedades debido a su baja capacidad de homeostasis y a la poca adaptabilidad a cambios bruscos del medio ambiente (Cárcamo \& Vallecillo, 2011) y (Alpuche et al., 2005). Esta teoría respalda lo observado en la investigación, una tendencia al aumento del número de casos con necrosis cuticular a medida que la temperatura se estaba acercando a los límites soportados por la especie L. vannamei. Además, la variación de la salinidad incidió en el aumento en el número de individuos con necrosis cuticular. Los factores ambientales tomados en consideración, temperatura y salinidad, marcaron tendencia inversamente proporcional reflejando las condiciones de manejo tecnológico de los estanques (Ramos Cruz \& Ramos Santiago, 2006).

La infección por Fusarium sp. se caracteriza por causar severas lesiones necróticas en branquias y exoesqueleto (Olvera et al., 2012), también pueden localizarse con frecuencia en los apéndices, tales como escamas de las antenas, flagelos antenales, pedúnculos oculares, pereiópodos, urópodos y telson. No es raro que lesiones en la cutícula debido a raspaduras, pérdidas de apéndices y punciones con la espina rostral, se infecten posteriormente con Fusarium (Cuellar et al., 2010). Se observó severas lesiones necróticas en diversas partes del exoesqueleto en varios especímenes, especialmente en periópodos, urópodos y telson tal como los describe Olvera et al. (2012).

Según Martínez, Caro y Bonifaz (2014), las especies de Fusarium están ampliamente distribuidas en el suelo y materia orgánica. En los juveniles y adultos de camarones peneidos, Fusarium es el género que ocasiona mayores problemas, la infección es progresiva y sirve como punto de entrada a otros patógenos oportunistas. En la investigación Fusarium fue la especie con mayor número de aislamientos.

Burgos, Farías, Torres y Ezquerra (2005) detectaron que el alimento para camarón presentaba el desarrollo de varios hongos toxigénicos, entre los que destacaban Aspergillus, Fusarium y Penicillium, exponiendo de esta forma al camarón cultivado al posible efecto dañino de estos contaminantes. En la población de camarones criados en la 
finca A, se identificó el hongo toxigénico, Penicillium un tipo de hongo causante de toxinas relacionadas con los alimentos. En el estudio se obtuvo datos similares a otros estudios realizados por Gómez, Roque y Guerra (2017) donde señalan la importancia de mantener un método rápido para la detección de este hongo y evitar su propagación.

Desde el punto de vista sanitario, la presencia de patógenos fúngicos como Aspergillus sp. Penicillium sp. y Fusarium sp., en las fincas consideradas, nos indican que pueden ser una enfermedad crónica debido a que los signos se han mantenido por muchos años; también puede ser considerada como una enfermedad reemergente, el manejo inapropiado de las buenas prácticas de producción acuícola es un factor condicionante para que se mantenga este tipo de enfermedades relacionadas con necrosis cuticular.

Aspergillus sp., es el principal productor de aflatoxinas (micotoxinas) y los ingredientes mayormente contaminados por aflatoxinas son el maíz, trigo, harina de semilla de algodón, granos utilizados como materia prima para alimento de camarones (Molina \& Villarreal, 2008).

Desde nuestro punto de vista, el aislamiento de Aspergillus sp., Penicillium sp y Fusarium $s p$. en las fincas muestreadas puede ser consecuencia del manejo inapropiado de las buenas prácticas de producción acuícolas relacionadas con factores contaminantes que pre condicionan su presencia en el alimento artificial (pellets), que es suministrado diariamente a los camarones en el sistema semi-intensivo de las fincas y coincide con lo que afirma Molina y Villarreal (2008). Cuellar et al. (2010) establece que las enfermedades producidas por micotoxinas no parecerían frecuentes e importantes en camarones peneidos de cultivo, pero las condiciones para que esto suceda, con frecuencia están presentes. La materia prima que se utilizó para la preparación del alimento que se proporciona a los animales en las fincas muestreadas, pudo estar contaminadas con esporas de estos hongos.

La presencia de Aspergillus sp. y Penicillium sp. en las colonias, también puede estar relacionado a que estos hongos son de origen terrestre y pueden llegar al medio marino arrastrados por el aire, la corriente de los ríos o la lluvia y adaptarse posteriormente a la salinidad (Briceño, 2009). 


\section{CONCLUSIONES}

En este estudio se confirma la presencia de necrosis cuticular $(55.76 \%)$ en las tres fincas muestreadas (Tabla 1).

Durante la luna nueva se presentó el mayor número de individuos con necrosis cuticular (51\%) y el incremento de la temperatura favoreció el aumento de individuos con dicha enfermedad. La disminución de la salinidad permitió la elevación del número de individuos necróticos.

Se observa, que independientemente de la tecnología empleada, están presentes los géneros de hongos: Fusarium sp., Aspergillus sp. y Penicillum sp., correspondiendo a la población de Fusarium sp. representan el 65\%, las de Aspergillus sp., $21 \%$ y Penicillum sp., $14 \%$.

Fusarium fue la especie con mayor número de aislamientos $(36 \%)$, a partir de tejido necrótico.

\section{RECOMENDACIONES}

Se sugiere investigaciones experimentales para corroborar variables externas que pueden estar influenciando en los camarones frente a la presencia de hongos patógenos que interfieren en la producción comercial.

\section{AGRADECIMIENTOS}

Al Profesor Lorenzo Becerra, Departamento de Biología Marina, Facultad de Ciencias Naturales, Exactas y Tecnología, Universidad de Panamá, C.R.U. de Coclé y a las Fincas Camaroneras de Aguadulce por la asistencia técnica brindada en esta investigación.

\section{REFERENCIAS}

Alpuche, J., Agundis, C., Solórzano, C. \& Pereyra, A. 2005. Lectina en L. Setiferus una alternativa en cultivo ante Enfermedades que Afectan al Cultivo de Camarones (Lectins from L. setiferus a possible solution for Culture Shrimp Diseases). Revista Electrónica de Veterinaria REDVET. ‥ ${ }^{\circ} 12$, pp. 1-12. 
Alvarado, P. 2005. Identificación de cepas patógenas de Fusarium causantes de nueva patología en el cultivo de calas de colores bajo condiciones productivas de invernadero en Chile (Tesis de pregrado). Universidad Austral de Chile.

Burgos, A., Farías, S., Torres, W., \& Ezquerra, J., (2005). In Vitro studies of the effects of aflatoxin B1 and fumonisin B1 on trypsin-like and collagenase-like activity from the hepatopancreas of white shrimp (Litopenaeus vannamei). Aquaculture. Vol 250.

Briceño, S. 2009. Microflora presente en muestras de camarones (Litopenaeus schmitti), Mejillones (Perna viridis) y Calamares (Loligo plei) congelados procesados en Cumaná, Estadio Sucre, Venezuela. Saber, Universidad de Oriente, Venezuela.Vol. 21. N. ${ }^{\circ}$ 2: 143-148.

Cañedo, V. \& Ames, T. (2004). Manual de Laboratorio para el Manejo de Hongos Entomopatógenos. Centro Internacional de la Papa (CIP), Lima, Perú.

Cárcamo Blanco, R. \& Vallecillo Ruíz, M. 2011. Comparación de dos condiciones de manejo del parámetro físico del agua (temperatura alta con retención de calor y con temperatura ambiente) sobre los parámetros poblacionales de camarón Litopenaeus vannamei en etapa de postlarva. (PL12-PL42 días).

Castro, V., Serrano, E. \& León, J. 2015. Aislamiento e identificación morfológica de Saprolegnia sp. en paiche (Arapaima gigas) proveniente de criaderos artesanales en Iquitos, Perú. Revista científica de la Sociedad Española de Acuicultura. n 41, 8-18 pp.

Cuéllar, J., Lara, C., Morales, V., De Gracia, A. \& Suarez, O. 2010. Manual de buenas prácticas de manejo para el cultivo del camarón blanco penaeus vannamei. OIRSAOSPESCA, C.A.

FAO. (2006). Programa de información de especies acuáticas Penaeus vannamei (Boone, 1931), Departamento de Pesca y Acuicultura. https:/C:/Users/HP/Documents/tesis/FAO\%20Fisheries\%20\&\%20Aq uaculture $\% 20 \% 20$ Programa $\% 20 \mathrm{de} \% 20$ información $\% 20 \mathrm{de} \% 20$ especie s\%20acuáticas\%20\%20Penaeus\%20vannamei\%20(Boone,\%201931).p df. 
García, S. \& Le Rest, L. 1986. Ciclos vitales, dinámica, explotación y ordenación de las poblaciones de camarones peneidos costeros. FAO. Documento Técnico de Pesca 203: 18.

Gómez, B., Roque, A. \& Guerra, L. 2017. Enfermedades Infecciosas más Comunes en la Camaronicultura en México y el Impacto del Uso de Antimicrobianos. Universidad Autónoma de Sinaloa, Mazatlán, México.

Jaime, B., Galindo, G., Laria, E., Cupul, F. \& Vega, F. 2008. Traslado de postlarvas de Litopenaeus vannamei (Boone, 1931) a diferentes tiempos, salinidades y densidades y su efecto en la supervivencia y algunos marcadores bioquímicos. Revista de Biología Marina y Oceanografía, 43(3) 681-686 pp.

Lozano Olvera, R., Marrujo López, F. I. \& Abad Rosales, S. M. 2012. Necrosis cuticular en camarón Litopenaeus vannamei asociada a Fusarium sp. Revista Electrónica de Veterinaria, Vol. 13, Núm. 7. Málaga, España.

Martínez, L., Caro, C. \& Bonifaz, A. 2014. Infecciones por Fusarium. México.

Molina, C. \& Villarreal, H. 2008. Estrategias de alimentación en la etapa de engorda del camarón. CIBNOR, S.A., CYTED y PRONACA, La Paz, B.C.S, México.

Moller, Ch. 1995. Manual Biolead Project. Switserland, 24-28 pp.

Morales Covarrubias, M. 2010. Análisis en fresco: herramienta para detección de alteraciones en camarones. Centro de Investigación en Alimentación y Desarrollo, A.C. Mazatlán, Sinaola, México.

Ochoa, N. 2004. Evaluación de factores de virulencia de hongos infecciosos en camarón blanco (Litopenaeus Vannamei) (tesis de grado). Instituto Politécnico Nacional, La Paz, B. C. S. México.

Olvera, L., López, M. \& Rosales, A. 2012. Necrosis cuticular en camarón Litopenaeus vannamei asociada a Fusarium sp. Revista Electrónica de Veterinaria, 13 (7): 1-7. 
Ramos Cruz, S. \& Ramos Santiago, E. 2006. Abundancia relativa de postlarvas de camarones peneidos en la Bahía Salinas del Marqués, Golfo de Tehuantepec, México. Marzo a junio de 1999. Revista de Biología Marina y Oceanografía 41(1): 121-128.

Roessler, MA, Jones, AC \& Munro, JL. 1969. Camarón rosado larval y postlarval, $P$. duorarum, en el sur de Florida. FAO Fish. Rep., (57) Vol. 3: 859-66.

Tizol, R., Jaime, B., Laria, R., Machado, R. \& Silveira, R. (2003). Introducción en Cuba del camarón blanco del pacifico L. vannamei. Etapa I cuarentena. Recuperado de: https://www.researchgate.net/publication/277239952_Introduccion_en _Cuba_del_camaron_blanco_del_pacifico_L_vannamei_Etapa_I_Cuar entena.

Uzcátegui, C., y Solano, J. 2016. Perspectiva sobre la sostenibilidad de los recursos naturales a largo plazo: caso industria camaronera ecuatoriana. Revista Universidad y Sociedad, 8(3): 163-168.

Recibido 15 de julio 2020 y aceptado 18 noviembre 2020. 